\title{
How Long is the Peer Review Process for Journal Manuscripts? A Case Study on Angewandte Chemie International Edition
}

\author{
Lutz Bornmannª and Hans-Dieter Danielab
}

\begin{abstract}
One of the most frequently raised criticisms of the review process for manuscripts is that the length of time between submission of a manuscript and the editorial decision is overly long. Taking the journal Angewandte Chemie International Edition as an example and based on nearly 2000 manuscripts, the present study examined just how long the peer review process takes.
\end{abstract}

Keywords: Journal peer review $\cdot$ Peer review time

\section{Introduction}

When research results are published, there are mainly two points in time that are very important. The first important time point is receipt of a manuscript at a journal's editorial office. In published journal articles, information such as the date on which a manuscript was received by the editors is often included. Recording this date makes it possible to settle possible priority disputes between researchers regarding certain original discoveries.[1] The second important time point is the date of publication: How long does it take for a manuscript to be reviewed, accepted for publication by the editors, and, finally, published? "Publication delays are of course frustrating to individual authors competing for recognition, but in the race for priority one author's loss is another's gain. More important is the aggregate delay in the dissemination of new knowledge, which represents a cost to the scientific community and general public."'[2]

One of the most frequently raised criticisms of manuscript reviewing is an overly long length of time between submission of

\footnotetext{
${ }^{*}$ Correspondence: Dr. L. Bornmann ${ }^{2}$

Tel.: +41446324825

Fax: 141446321283

aProfessorship for Social Psychology and Research

on Higher Education

ETH Zurich

Zähringerstrasse 24

$\mathrm{CH}-8092$ Zurich

bEvaluation Office

University of Zurich
}

a manuscript and the editorial decision. ${ }^{[3]}$ Hames, ${ }^{4]}$ writes, for example, that "critics of peer review cite examples that point to ... it being labour intensive, expensive, and often slow, with resulting delays in publication" (p. 2). A survey of 3040 authors whose papers had been recently published in a journal indexed in Web of Science (provided by Thomson Reuters, Philadelphia, PA, USA) found that "there was evidence that peer review is too slow (38\% were dissatisfied with peer review times)."'[5, p.1] But even though manuscript reviewing is often criticized for slowness, only few studies have been published that investigated the time it takes for the peer review process empirically. ${ }^{[6-10]}$

The peer review process at the journal Angewandte Chemie International Edition (AC-IE) was examined in the context of a comprehensive research project. ${ }^{[11-14]} \mathrm{AC}$ IE is one of the prime chemistry journals in the world, with a higher annual Journal Impact Factor (provided by Thomson Reuters) than the Journal Impact Factors of comparable journals (at 10.879 in the 2008 Journal Citation Reports, Science Edition). AC-IE is owned by the German Chemical Society (Gesellschaft Deutscher Chemiker (GDCh), Frankfurt am Main, Germany) and published by Wiley-VCH (Weinheim, Germany). What the editors of AC-IE look for most of all is excellence in chemical research. Manuscripts that reviewers (and editors) deem to be of high quality are selected for publication. Manuscripts that do not meet the high standards are rejected.

The present study examined the length of time it takes for the peer review process, taking AC-IE as a case study. The object was to answer questions such as have been raised in a similar form by Jennings, ${ }^{[2]}$ former executive editor of the Nature re- search journals: ${ }^{[15]}$ How long is the interval from submission to the editorial decision, and how much of this is attributable to the external review process? How much time do referees expend on reviewing? In addition, the present study examines a number of further topics, such as the length of time it takes for different kinds of reviews (such as an initial review of a submitted manuscripts, or a review of an appeal), beating or missing deadlines for submission of reviews to the editorial office, and the average length of time to complete a review by referees that very often reviewed manuscripts for AC-IE during the research study period.

\section{Methods}

\subsection{Manuscript Reviewing at AC-IE}

A manuscript submitted to AC-IE is usually subject to internal and external reviewing. First, editors at the journal evaluate whether the manuscript contributes to the development of an important area of research (internal evaluation). The editors are full-time members of the editorial staff. If the editors find that a manuscript is an important contribution, the submission is usually sent to three independent referees (external evaluation). The referees are asked to return their reviews to the editorial office within two weeks. This is a very short time period compared to the deadlines given referees by other journals; a survey of editors of various journals found that the deadline for reviewers is usually 3-4 weeks. ${ }^{[16]}$ AC-IE therefore tries to guarantee rapid reviewing of submitted manuscripts.

The referees use an evaluation form together with a separate sheet for comments (a comment sheet). The evaluation form 
contains a set of six questions and associated response categories. In addition to initial external reviews for a submission, additional review requests for a part of the manuscripts are given to referees: The editor (1) consults a top adviser for manuscript review or (2) has referees review manuscripts revised by the authors or (3) has referees review appeals that authors filed against the rejection of their manuscript. ${ }^{[17]}$ At the end of a review process, a staff editor makes the decision to accept or reject a manuscript for publication on the basis of the requested reviews and on their own evaluations. For most submissions a manuscript is published only if two external referees rate the results of the study reported in the manuscript as (very) important and also recommend publication in the journal. ${ }^{[13,17]}$

AC-IE introduced peer review in 1982, primarily in conjunction with one of the document types published in the journal, Communications, which are short reports on work in progress or recently concluded experimental or theoretical investigations. A Communication is expected to be of broad general interest, due to its significance, novelty, or wide applicability, or at least to be of special utility in the development of some important areas of research. It must also be written in such a way that even a non-specialist will recognize the significance that the author attaches to the findings. ${ }^{[18]}$

\subsection{Database for the Present Study}

For the investigation of the length of time it takes for manuscript reviewing at AC-IE, information on a total of 1899 manuscripts was used; the manuscripts had been submitted by the authors in order to be published as Communications and were reviewed in the year 2000. By using the manuscripts reviewed in 2000, a somewhat older manuscript cohort was selected as the database, since for an examination of the predictive validity of the editorial decisions ${ }^{[11,12]}$ there should be a time interval of several years between the reviewing of a manuscript and measurement of the indicator for scientific quality (in this case: citations). The information on the manuscripts was taken from archived material that was stored electronically by the publisher, Wiley-VCH. Of the 1899 manuscripts, $46 \%(n=878)$ were accepted for publication in AC-IE, and 54\% ( $n=$ 1021) were rejected. The editorial decision to accept or reject a manuscript was made for 1896 manuscripts based on an external review. No external review was done for three manuscripts in the data set of this study, and the editor rejected the manuscripts (without external review). [19]

\subsection{Statistical Procedure}

To test whether differences in the average length of time (for example, the average length of time from submission of a manuscript to the editorial decision) for two independent samples (e.g. accepted or rejected manuscripts) were statistically significant, the Wilcoxon-MannWhitney test was computed. Where there were more than two independent samples, the Kruskal Wallis test was used instead. The Chi-square test was used for testing statistical significance in the kxk tables. Since the result of the statistical significance test is dependent on sample size and "statistical significance does not mean real life importance", $[20, p .290]$ it is the strength of the association that is more interesting and important for interpreting the empirical finding. For calculating strength, we have to employ an additional measure of association. We used Cramer's V to test the association between two nominal variables (such as beating or missing the deadline for submission of reviews to the editorial office und the reviewer's country of residence). According to Kline, ${ }^{[21]} \mathrm{V}$ "is probably the best known measure of association for contingency tables" (p. 151). Where the two variables were a nominal variable (for example, editorial decision: accept or reject for publication) and an interval variable (for example, the length of time from submission of a manuscript to the editorial decision), Eta ( $\eta$ ) was computed as the measure of association. The effect sizes $(\eta$ and $\mathrm{V}$ ) were interpreted as small, medium, and large following the widely accepted suggestions of Cohen. ${ }^{[22]}$

\section{Results}

Table 1 shows the number of weeks from receipt of a manuscript at the ACIE editorial office and the editorial decision to accept or reject for publication. As the Table reveals, decisions were made on about one-quarter of the manuscripts within three weeks; the process took four weeks for about $20 \%$ of the manuscripts. The review process took nine weeks or longer for about a further $20 \%$ of the manuscripts. As Table 2 shows, the average length of time between receipt of a manuscript at the $\mathrm{AC}$ IE editorial office and the editorial decision on publication was 6.8 weeks (arithmetic average, median $=5$ ). Comparison figures are available for the journals Indian Pediatrics $^{[7]}$ and four American Fisheries Society journals:[23] "Median number of days (IQR) needed to reach the final decision was $81 ",[7, p .485]$ or in other words, about 11 to 12 weeks. "Overall time from submission
Table 1. Number of weeks between receipt of manuscript at the editoria office and the editorial decision to accept or reject for publication

\begin{tabular}{llll} 
Number of weeks & $n$ & Percent & Cumulated percent \\
\hline Less than 3 & 125 & 6.6 & 6.6 \\
3 & 315 & 16.6 & 23.2 \\
4 & 367 & 19.4 & 42.6 \\
5 & 283 & 14.9 & 57.6 \\
6 & 193 & 10.2 & 67.7 \\
7 & 144 & 7.6 & 75.3 \\
8 & 84 & 4.4 & 79.8 \\
9 to 12 & 167 & 8.8 & 88.6 \\
13 to 16 & 96 & 5.1 & 93.7 \\
17 to 20 & 55 & 2.9 & 96.6 \\
21 to 62 & 65 & 3.4 & 100 \\
\hline Total & 1894 & 100 & \\
\hline
\end{tabular}

Note: For five manuscripts, the date of receipt and/or decision is not known.
Table 2. Average number of weeks between receipt of manuscript at the editorial office and editorial decision to accept or reject for publication, in dependency on editorial decision

$\begin{array}{llll}\text { Statistic } & \text { Acceptance } & \text { Rejection } & \text { Total } \\ \text { Number of manuscripts } & 877 & 1017 & 1894 \\ \text { Median } & 5 & 5 & 5 \\ \text { Arithmetic mean } & 7.51^{\mathrm{a}} & 6.18^{\mathrm{a}} & 6.80 \\ \text { Standard deviation } & 6.04 & 5.35 & 5.72 \\ \text { Minimum } & 0 & 0 & 0 \\ \text { Maximum } & 41 & 62 & 62\end{array}$

Notes. In the table, 0 means that the manuscript was received at the editorial office and the publication decision was made within one week.

${ }^{a} Z=-5.71, P<.05, \eta=.12$. 
to the first editor decision (i.e. not including manuscript revisions) remains at about 13.4 weeks for AFS journals (data combined for all four AFS journals)".[23,p.272] A survey of 3040 authors $^{[5]}$ (see above) reported similar findings. As compared to the results of these two studies, the peer review process at ACIE can be considered to be extremely short.

In addition to the average number of weeks, Table 2 also shows the shortest (within the first week) and the longest (62 weeks) length of time for the entire peer review process for a manuscript up to the editorial decision. Here, some comparison figures on another journal, namely, Condensed Matter Physics, are available: "The maximal time of the paper processing is equal to $\tau \max =600$ days (volume 9 , No. 1(21), p. 175-182), the minimal one is equal to four days (volume 7, No. 4, p. 829-844; volume 7, No. 4, p. 845-858)".[6,p.138] Just as was the case for the average length of time for the peer review process, here again AC-IE shows clearly shorter minimum and maximum values than another journal (here it is Condensed Matter Physics). Table 2 also shows the average number of weeks for the total reviewing time classified according to accepted and rejected manuscripts. In agreement with findings by Stamm et al. ${ }^{[8]}$ for the journal Head \& Face Medicine, the results show that the reviewing time for accepted manuscripts ( 7.51 weeks) was on average about one week longer than the reviewing time for rejected manuscripts $(6.18$ weeks). The difference between the reviewing times is statistically significant, but the effect size is small.

Table 3 shows the average number of weeks it took for referees that completed more than nine initial reviews within the time period studied to complete the review. The results in the table indicate that $\mathrm{AC}$-IE referees require different lengths of time to review a manuscript: Whereas Referees A and $\mathrm{B}$ produced reviews within about three weeks on average, Referees $\mathrm{BB}$ and $\mathrm{CC}$ produced reviews within a few days' time. The difference between the average reviewing times of individual referees is statistically significant, and the effect size is large. However, it is noticeable that among referees that have relatively long average reviewing times, the minimum and maximum reviewing times are clearly different. Hence they, too, have produced reviews for AC-IE in a relatively short period of time. When interpreting the figures in Table 3 , it should be considered that they refer to only 344 of the total of 1896 manuscripts. 'Heavy' referees tend to be the exception: A large part of the manuscripts in the data set of this study were reviewed by referees that reviewed no other or only one other manuscript for ACIE during the observation period.

Table 4 reports the average number of weeks that it took for referees to complete different kinds of reviews (see above). As the 'Total' column shows, the average length of time to complete the reviews was 2.13 weeks. Whereas initial reviews of a submission (2.2 weeks) took the longest to complete, reviews by top advisers (1.41 week) took the shortest time. Although the difference between the average numbers of weeks for the different kinds of reviews is statistically significant, the effect size is small. For Gölitz, ${ }^{[24]}$ the chief editor of AC-IE, the general quick turnaround for reviews is "especially impressive when one considers that the referees of manuscripts for Angewandte Chemie (and other

top journals) devote a great deal of effort to their evaluations. This is not to say that deficiencies or errors in manuscripts are never overlooked by the referees and editors of this journal" (p. 5030). Green and Callaham ${ }^{[9]}$ found short review times similar to those at AC-IE for the journal Annals of Emergency Medicine: from 10 to 12 days on average (median). Other studies report clearly longer review times: "The peer review time for the first and second reports were 33.8 and 41.9 days, respectively. In total, the mean PRT was 37.8 days, which comes in shorter than the six-weeks turnaround time the Editors set themselves as

Table 3. Average number of weeks that it took for 29 different referees to produce an initial review (each referee completed more than nine initial reviews during the time period under study) (in descending order by arithmetic average)

\begin{tabular}{|c|c|c|c|c|c|c|}
\hline Reviewer & $\begin{array}{l}\text { Number of } \\
\text { reviews }\end{array}$ & Median & $\begin{array}{l}\text { Arithmetic } \\
\text { average }\end{array}$ & $\begin{array}{l}\text { Standard } \\
\text { deviation }\end{array}$ & Minimum & Maximum \\
\hline$A$ & 12 & 3 & $2.67^{a}$ & 1.15 & 1 & 5 \\
\hline$B$ & 16 & 2 & $2.63^{a}$ & 1.50 & 1 & 6 \\
\hline C & 15 & 2 & $2.40^{\mathrm{a}}$ & .74 & 1 & 4 \\
\hline D & 10 & 2 & $2.30^{a}$ & 1.16 & 1 & 5 \\
\hline$E$ & 10 & 2 & $2.20^{\mathrm{a}}$ & 1.03 & 1 & 4 \\
\hline$F$ & 10 & 2 & $2.20^{\mathrm{a}}$ & .92 & 0 & 3 \\
\hline G & 10 & 2 & $2.20^{\mathrm{a}}$ & 1.81 & 0 & 5 \\
\hline $\mathrm{H}$ & 10 & 2 & $2.10^{a}$ & .32 & 2 & 3 \\
\hline 1 & 13 & 2 & $1.92^{\mathrm{a}}$ & 1.38 & 0 & 5 \\
\hline J & 11 & 2 & $1.91^{\mathrm{a}}$ & .70 & 1 & 3 \\
\hline K & 12 & 2 & $1.83^{a}$ & .83 & 1 & 3 \\
\hline $\mathrm{L}$ & 10 & 2 & $1.80^{\mathrm{a}}$ & 1.32 & 0 & 4 \\
\hline M & 10 & 2 & $1.80^{\mathrm{a}}$ & .79 & 1 & 3 \\
\hline $\mathrm{N}$ & 15 & 1 & $1.60^{\mathrm{a}}$ & .99 & 0 & 4 \\
\hline 0 & 10 & 2 & $1.60^{\mathrm{a}}$ & 1.07 & 0 & 3 \\
\hline$P$ & 11 & 2 & $1.45^{\mathrm{a}}$ & .69 & 0 & 2 \\
\hline $\mathrm{Q}$ & 11 & 1 & $1.36^{a}$ & .92 & 0 & 3 \\
\hline $\mathrm{R}$ & 14 & 1 & $1.29^{a}$ & .61 & 0 & 2 \\
\hline S & 10 & 1 & $1.20^{\mathrm{a}}$ & .42 & 1 & 2 \\
\hline $\mathrm{T}$ & 16 & 1 & $1.19^{a}$ & .40 & 1 & 2 \\
\hline U & 11 & 1 & $1.18^{a}$ & .75 & 0 & 2 \\
\hline V & 12 & 1 & $1^{\mathrm{a}}$ & .85 & 0 & 3 \\
\hline W & 12 & 1 & $.92^{a}$ & .79 & 0 & 2 \\
\hline$X$ & 11 & 1 & $.91 \mathrm{a}^{\mathrm{a}}$ & .94 & 0 & 3 \\
\hline$Y$ & 14 & .50 & $.79^{a}$ & .89 & 0 & 2 \\
\hline Z & 10 & 1 & $.70^{\mathrm{a}}$ & .67 & 0 & 2 \\
\hline AA & 12 & 0 & $.42^{a}$ & .79 & 0 & 2 \\
\hline BB & 13 & 0 & $.38^{a}$ & .51 & 0 & 1 \\
\hline $\mathrm{CC}$ & 13 & 0 & $.31^{a}$ & .48 & 0 & 1 \\
\hline
\end{tabular}

Notes. In the table, 0 means that referee completed the initial review within one week. ${ }^{a} \chi_{28}^{2}=134.8, P<.05, \eta=.60$. 
the maximum". ${ }^{[8]}$ As the survey conducted by Publishing Research Consortium ${ }^{[5]}$ reported, "reviewers say that they took about 24 days (elapsed time) to complete their last review, with $85 \%$ reporting that they took 30 days or less" (p. 3).

In a further analysis step, the present study examined the extent to which the average number of weeks it took for a referee to complete a review depends on the referee's recommendation. For the journal Indian Pediatrics Gupta et al..$^{[7]}$ found that the peer review time "of rejected manuscripts was shorter (35.3 days) when compared to accepted papers (40.3 days), but not to a significant extent ( $\mathrm{p}>0.05)$ " ( $\mathrm{p}$. 485). Table 5 shows the average number of weeks that it took for a reviewer to complete initial review, in dependency on the referee's answer to the question, "Do you recommend acceptance of the Communication?" Contrary to the findings by Gupta et al., ${ }^{[7]}$ there is a statistically significant difference between the mean review times (a review with the recommendation, "Yes, without alterations" took the least time to complete on average (1.93 weeks), and a review with the recommendation, "Yes, but only after major alterations" the longest time (2.32 weeks), but here again, the effect size is (very) small.

As an international journal, the AC-IE sends review requests to referees from a number of different countries, as can be seen in Table 6 . We examined whether the average number of weeks it took for referees to complete initial reviews differed between referees living in different countries. As the table reveals, referees from East Asia and North America took the longest time on average to complete reviews (3.08 and 2.97 weeks, respectively), and referees from Western Europe (core) and Eastern Europe took the shortest time on average (2.03 and 1.92 weeks). The difference between the mean times to complete the reviews is statistically significant, and the effect size is small. We also examined the extent to which referees from the different countries differed with regard to beating or missing the deadline for submitting an initial review to the AC-IE editorial office. Table 7 shows the results, but before presenting them, we will report some general figures on beating or missing the deadline for submitting an initial review to the AC-IE editorial office.

Of the 2921 reviews for which the deadline for submission of the review and the date on which the review was received at the editorial office are known, $55 \%(\mathrm{n}=$ 1595) were received by the editors a few days early, exactly on time, or a few days late. The editors received $13 \%$ of the reviews $(n=390)$ one week before the due date and $16 \%(n=462)$ of the reviews one week after the due date; $16 \%$ of the reviews
Table 4. Average number of weeks that it took for referees to complete different kinds of reviews

\begin{tabular}{|c|c|c|c|c|c|}
\hline Statistic & $\begin{array}{l}\text { Initial re- } \\
\text { view of a } \\
\text { submission }\end{array}$ & $\begin{array}{l}\text { Review of a } \\
\text { manuscript } \\
\text { revised by } \\
\text { the author }\end{array}$ & $\begin{array}{l}\text { Review of a } \\
\text { manuscript and } \\
\text { of initial refer- } \\
\text { ees' comments } \\
\text { by a top adviser }\end{array}$ & $\begin{array}{l}\text { Review of an } \\
\text { author's ap- } \\
\text { peal against the } \\
\text { rejection of a } \\
\text { manuscript }\end{array}$ & Total \\
\hline $\begin{array}{l}\text { Number of } \\
\text { manuscripts }\end{array}$ & 4016 & 304 & 113 & 134 & 4567 \\
\hline Median & 2 & 1 & 1 & 1 & 2 \\
\hline Arithmetic mean & $2.20^{a}$ & $1.64^{a}$ & $1.41^{\mathrm{a}}$ & $1.72^{\mathrm{a}}$ & 2.13 \\
\hline $\begin{array}{l}\text { Standard } \\
\text { deviation }\end{array}$ & 1.59 & 1.50 & 1.32 & 1.39 & 1.59 \\
\hline Minimum & 0 & 0 & 0 & 0 & 0 \\
\hline Maximum & 11 & 9 & 6 & 7 & 11 \\
\hline
\end{tabular}

Notes. In the table, 0 means that referees completed the review within one week.

${ }^{\mathrm{a}} \chi_{3}^{2}=94.8, P<.05, \eta=.12$.

Table 5. Average number of weeks that it took for a referee to complete an initial review, in dependency on referee's recommendation

\begin{tabular}{|c|c|c|c|c|c|}
\hline \multirow[b]{2}{*}{ Statistic } & \multicolumn{5}{|c|}{ Do you recommend acceptance of the Communication? } \\
\hline & $\begin{array}{l}\text { Yes, without } \\
\text { alterations }\end{array}$ & $\begin{array}{l}\text { Yes, after minor } \\
\text { alterations }\end{array}$ & $\begin{array}{l}\text { Yes, but only after } \\
\text { major alterations }\end{array}$ & No & Total \\
\hline $\begin{array}{l}\text { Number of } \\
\text { manuscripts }\end{array}$ & 386 & 1017 & 513 & 1537 & 3453 \\
\hline Median & 2 & 2 & 2 & 2 & 2 \\
\hline Arithmetic mean & $1.93^{\mathrm{a}}$ & $2.21^{a}$ & $2.32^{\mathrm{a}}$ & $2.14^{\mathrm{a}}$ & 2.16 \\
\hline $\begin{array}{l}\text { Standard } \\
\text { deviation }\end{array}$ & 1.52 & 1.55 & 1.66 & 1.53 & 1.56 \\
\hline Minimum & 0 & 0 & 0 & 0 & 0 \\
\hline Maximum & 11 & 9 & 10 & 11 & 11 \\
\hline
\end{tabular}

Notes. In the table, 0 means that referee completed the initial review within one week. ${ }^{a} \chi_{3}^{2}=16.3, P<.05, \eta=.07$.

Table 6. Average number of weeks that it took for a referee to complete an initial review, in dependency on the referee's country of residence (in descending order by arithmetic mean)

\begin{tabular}{|c|c|c|c|c|c|c|}
\hline Country & $\begin{array}{l}\text { Number of } \\
\text { manuscripts }\end{array}$ & Median & $\begin{array}{l}\text { Arithmetic } \\
\text { mean }\end{array}$ & $\begin{array}{l}\text { Standard } \\
\text { deviation }\end{array}$ & Minimum & Maximum \\
\hline East Asia & 24 & 3 & $3.08^{a}$ & 1.35 & 1 & 6 \\
\hline North America & 669 & 3 & $2.97^{a}$ & 1.74 & 0 & 11 \\
\hline Australia & 35 & 3 & $2.63^{a}$ & 1.65 & 0 & 9 \\
\hline Japan & 156 & 2 & $2.09^{a}$ & 1.37 & 0 & 6 \\
\hline $\begin{array}{l}\text { Western Europe } \\
\text { (periphery, e.g. } \\
\text { Sweden) }\end{array}$ & 142 & 2 & $2.09^{a}$ & 1.62 & 0 & 8 \\
\hline $\begin{array}{l}\text { Western Europe } \\
\text { (core, e.g. } \\
\text { Germany) }\end{array}$ & 2943 & 2 & $2.03^{a}$ & 1.52 & 0 & 11 \\
\hline Eastern Europe & 12 & 2 & $1.92^{\mathrm{a}}$ & 0.79 & 1 & 3 \\
\hline $\begin{array}{l}\text { Others (e.g. } \\
\text { India) }\end{array}$ & 20 & 2 & $2.30^{\mathrm{a}}$ & 1.42 & 1 & 5 \\
\hline Total & 4001 & 2 & $2.20^{\mathrm{a}}$ & 1.60 & 0 & 11 \\
\hline
\end{tabular}

Notes. In the table, 0 means that referee completed the initial review within one week. ${ }^{\mathrm{a}} \chi_{7}^{2}=208.7, P<.05, \eta=.23$. 
Table 7. Beating or missing the deadline for submitting an initial review to the AC-IE editorial office, in dependency on the referee's country of residence (in percent, $n=2451$ )

$\begin{array}{lllll}\begin{array}{l}\text { Beating or missing the } \\ \text { deadline }\end{array} & \begin{array}{l}\text { Japan } \\ (\mathrm{n}=91)\end{array} & \begin{array}{l}\text { North } \\ \text { America } \\ (\mathrm{n}=301)\end{array} & \begin{array}{l}\text { Western Europe } \\ (\text { core, e.g. Germany }) \\ (\mathrm{n}=1985)\end{array} & \begin{array}{l}\text { Western Europe } \\ \text { (periphery, e.g. } \\ \text { Sweden) }(\mathrm{n}=74)\end{array} \\ \begin{array}{l}\text { Beat the deadline by } \\ \text { more than 1 week }\end{array} & 10 & 3 & 15 & 24 \\ \begin{array}{l}\text { On time or a few days } \\ \text { before or after the } \\ \text { deadline }\end{array} & 59 & 48 & 55 & 50 \\ \begin{array}{l}\text { Missed the deadline by } \\ \text { more than 1 week }\end{array} & 31 & 49 & 30 & 26 \\ \begin{array}{l}\text { Total } \\ \text { Stal }\end{array} & 100 & 100 & 100 & 100\end{array}$

Notes. $\chi_{6}^{2}=70.4, P<.05, \mathrm{~V}=.12$.

Due to low numbers of cases, initial reviews of referees from Australia $(n=11)$, East Asia $(n=15)$, Eastern Europe $(n=7)$, and other countries $(n=6)$ were not included in the analysis.

Table 8. Amount of the entire time from submission of a manuscript to the editorial decision that is attributable to external reviewing (in descending order by arithmetic mean)

$\begin{array}{lllll}\text { Review sequence } & \begin{array}{l}\text { Number of } \\ \text { manuscripts }\end{array} & \text { Arithmetic mean } & \begin{array}{l}\text { Standard } \\ \text { deviation }\end{array} & \text { Median } \\ \text { SM |SM |SM |OO }|\mathrm{OO}| \mathrm{OO}|\mathrm{OO}| \mathrm{OO} & 382 & 72.66^{\mathrm{a}} & 16.05 & 75.61 \\ \mathrm{SM}|\mathrm{SM}| \mathrm{SM}|\mathrm{SM}| \mathrm{OO}|\mathrm{OO}| \mathrm{OO} \mid \mathrm{OO} & 17 & 68.12^{\mathrm{a}} & 19.46 & 75.00 \\ \mathrm{SM}|\mathrm{SM}| \mathrm{OO}|\mathrm{OO}| \mathrm{OO}|\mathrm{OO}| \mathrm{OO} \mid \mathrm{OO} & 939 & 67.84^{\mathrm{a}} & 16.04 & 70.37 \\ \mathrm{SM}|\mathrm{SM}| \mathrm{TA}|\mathrm{OO}| \mathrm{OO}|\mathrm{OO}| \mathrm{OO} \mid \mathrm{OO} & 64 & 67.54^{\mathrm{a}} & 15.56 & 70.94 \\ \mathrm{SM}|\mathrm{SM}| \mathrm{SM}|\mathrm{AP}| \mathrm{OO}|\mathrm{OO}| \mathrm{OO} \mid \mathrm{OO} & 12 & 60.31^{\mathrm{a}} & 19.70 & 55.98 \\ \mathrm{SM}|\mathrm{SM}| \mathrm{SM}|\mathrm{RE}| \mathrm{OO}|\mathrm{OO}| \mathrm{OO} \mid \mathrm{OO} & 37 & 56.82^{\mathrm{a}} & 17.80 & 56.34 \\ \mathrm{SM}|\mathrm{SM}| \mathrm{RE}|\mathrm{RE}| \mathrm{OO}|\mathrm{OO}| \mathrm{OO} \mid \mathrm{OO} & 13 & 54.27^{\mathrm{a}} & 21.02 & 54.86 \\ \mathrm{SM}|\mathrm{SM}| \mathrm{RE}|\mathrm{OO}| \mathrm{OO}|\mathrm{OO}| \mathrm{OO} \mid \mathrm{OO} & 49 & 51.04^{\mathrm{a}} & 19.60 & 45.24 \\ \mathrm{SM}|\mathrm{SM}| \mathrm{SM}|\mathrm{RE}| \mathrm{RE}|\mathrm{OO}| \mathrm{OO} \mid \mathrm{OO} & 22 & 47.42^{\mathrm{a}} & 15.86 & 47.92 \\ \mathrm{SM}|\mathrm{SM}| \mathrm{AP}|\mathrm{OO}| \mathrm{OO}|\mathrm{OO}| \mathrm{OO} \mid \mathrm{OO} & 20 & 43.71^{\mathrm{a}} & 16.46 & 39.64 \\ \mathrm{SM}|\mathrm{OO}| \mathrm{OO}|\mathrm{OO}| \mathrm{OO}|\mathrm{OO}| \mathrm{OO} \mid \mathrm{OO} & 118 & 40.62^{\mathrm{a}} & 23.20 & 37.23 \\ \text { Total } & 1673 & 65.56 & 19.00 & 69.39\end{array}$

Notes. This table includes only review sequences that were found in the dataset more than ten times.

Abbreviations. |SM|: Initial review of a submitted manuscript; |TA|: review by a top adviser; |RE|: review of a revised manuscript; |AP|: review of an appeal.

Differences in the number of cases between this table and Table 8 in Bornmann and Daniel[17] are due to the fact that here, only those manuscripts are included for which the dates were available for the following: (1) receipt at the AC-IE editorial office, (2) publication decision made, (3) start and end of each external review.

${ }^{\mathrm{a}} \chi^{2}{ }_{10}=272.1, P<.05, \eta=.46$.

$(n=474)$ arrived at the editorial office from two to nine weeks late. Whether a review was turned in before or after the due date for submission did not depend on what kind of review request by an editor a referee was fulfilling $\left(\chi_{6}^{2}=11.0, P=.09, \mathrm{~V}=.04\right)$ or on what recommendation regarding publication that the referee made (when pertaining to initial reviews, $\chi_{6}^{2}=7.1, P=.32, \mathrm{~V}=$ .04 ); but as Table 7 shows, the time point is dependent on the referee's country of residence - but with a small effect size. Whereas about $30 \%$ of the initial reviews that were submitted from Japan or Western Europe were turned in at least one week late, $49 \%$ of the initial reviews from North America were submitted at least one week late.

The last analysis step in the present study was to breakdown the entire time from submission of a manuscript to the editorial decision to accept for reject for publication, examining for each manuscript the portion of that time that is attributable to external reviewing (the remaining time is then attributable to the authors and editors). If for one manuscript the reviews of several referees overlapped in time, we used for the computation one single time period with the earliest and latest time points. For 1756 manuscripts the complete data required for this analysis was available: the date on which (1) the manuscript was received by the $\mathrm{AC}$-IE editorial office, (2) the decision was made to accept or reject for publication, and (3) the start and end of each external review. Of the 1756 manuscripts, 16 could not be included in the analysis, as after the publication decisions was made (acceptance for publication), there was another review of the manuscript after the author completed revisions. That is, after the time between submission of the manuscript and the editorial decision further reviews took place.

As the results show, the average portion of the entire time from submission of a manuscript to the editorial decision that is attributable to external reviewing was $65 \%$ (arithmetic average, median $=69 \%$ ); thus, approximately $35 \%$ of the entire time period is attributable to the authors (for revising the manuscript, for example) and/or the editors (for choosing the external referees, for example). (Somewhat lower percentages are reported for four American Fisheries Society journals: "between 51 to $60 \%$ of the time between manuscript submission and initial editor decision".[23,p.272]) It can be assumed that the external reviewing portion of the entire time required for the peer review process depends on the course/ sequence of events of the process. For instance, if an author appeals rejection of a manuscript and the editors sent the manuscript out for review once again, the time for external reviewing will be a smaller portion of the entire time, as that entire time now includes the time it takes for the author's appeal and for the editors to decide whether the manuscript should be reviewed once again. Table 8 presents the portion of the entire time from submission of a manuscript to the editorial decision that is attributable to external reviewing, broken down according to various review sequences.

In order to establish in the statistical analysis for each submission the sequence with the individual review steps, the following categories are used with which the review requests were summarized: (1) initial review of a submitted manuscripts (SM), (2) review by a top adviser (TA), (3) review of a revised manuscript (RE), and (4) review of an appeal (AP). As is shown in Bornmann and Daniel, ${ }^{[17]}$ there are a total of 55 different review sequences for the 1896 manuscripts submitted to AC-IE. Table 8 shows the eleven sequences that occur more frequently than ten times in the data set. For each sequence, the mean portion of the entire peer review process time for external reviewing is shown in the Table. The difference between the individual review sequences in mean time is statistically significant, and the effect size is large. As expected, this amount of time is greatest when there are no reviews by a top adviser (TA), reviews of a revised manuscript, or reviews of an appeal (AP) in 
addition to the initial reviews (SM). Those other reviews are usually associated with more time expended on the part of the staff editors and/or authors.

The 118 manuscripts in Table 8 for which the editorial decision was based on only one review are an exception. The reason why for these manuscripts the average time (at $40.62 \%$ ) is the smallest portion of the entire peer review processing time when compared to the other review sequences is that an AC-IE editor usually waits for a second review before making a decision as to publish or not publish a manuscript (see Section 2). Making the publication decision based on only one review is justified as in the following letter in which an AC-IE editor explained the rejection of a manuscript to an author: "We hope that you will understand our decision, which is in accord with the opinion of one referee only. The second referee did not answer despite several reminders. However, since we have to reject almost all manuscripts that do not receive two clear-cut recommendations I return your manuscript without waiting any longer. If we receive the second referee comment, we'll forward it without further comments". For these 118 manuscripts, the small average portion of the entire peer review process time for external reviewing is attributable mainly to the editor's waiting time.

\section{Discussion}

Taking the example of the journal ACIE, this study investigated the length of time required for the peer review process. As the results show, the entire peer review process at AC-IE is clearly shorter than that at other journals. However, when interpreting this result it must be taken into consideration that this study is based exclusively on manuscripts that are intended to be published as Communications (see Section 2); Communications are short reports limited to six manuscript pages. Scientists publish research results in the form of Communications in order to speed publication. The Journal of the American Chemical Society ${ }^{[25]}$ stresses this criterion of urgency in its own definition: "Communications are restricted to reports of unusual urgency, timeliness, significance, and broad interest" (p. 20A). "The immediacy and the short length of the reports of research findings are hence important features that distinguish Communications from research articles and reviews".[26] From 1984 to 2007 the number of Communications submitted to AC-IE rose from 449 to $5489,[18,27]$ and this trend is continuing. Thus, when reviewing Communications the staff editors are under considerable pressure to reach rapid publication decisions.
At approximately two weeks, the time that it takes for an AC-IE reviewer to submit a review is - similar to the entire time required for the peer review process at $\mathrm{AC}$-IE - very short. A study also on the journal ACIE by Gölitz, ${ }^{[24]}$ but investigating a younger submission cohort, yielded a similar result: "The referee process is quite fast: referee reports arrive on average (!) 13 days after being requested" (p. 5030). As the further analyses of our study regarding the length of time required for the completing of a review show, some referees appear on average to require more time than other referees, but also the altogether comparatively slow referees were able to complete reviews within one week or faster during the period of time under study. The small effect sizes found in a number of the analyses in the present study indicate that the time it takes for an external referee to produce a review is hardly dependent upon the review request, the referee's recommendation, or the referee's country of residence.

In a last analysis step the present study examined how much of the entire time for the peer review process is attributable to the external reviewing. This was found to be about $65 \%$ across all manuscripts, ranging from $41 \%$ to $73 \%$ in dependency on the particular review sequence. Thus, about two-thirds of the entire time required for the peer review process was attributable to the reviewing scientists; about one-third of the entire time was attributable to the manuscript authors and/or the journal editors. It must be noted that this study on the length of the peer review process was based on a specific data set, namely, on manuscripts intended to be published as Communications. The findings will therefore not be applicable without restrictions to journals that publish mainly full papers and/or reviews. Unfortunately, no studies with findings that could be used for comparison have been published.

All in all, the present study provides one of the few in-depth evaluations of the amount of time required for the peer review process. In view of the frequent objections that have been raised in the literature to the supposed overly long period of time between submission of a manuscript and the editorial decision, it is surprising that there are hardly any studies on the topic. The present study presents robust findings that should be complemented by findings from further studies on further journals (and also in disciplines other than chemistry).

\section{Acknowledgements}

The entire research study, which is also investigating quality assurance of open access journals, is supported by a grant from the Max Planck Society. We thank Dr. Peter Gölitz, Editor-in-Chief of Angewandte Chemie, the Editorial Board of Angewandte Chemie, and the
German Chemical Society (GDCh, Frankfurt am Main, Germany) for permission to conduct the evaluation of the selection process of the journal, and thank the members of the editorial office for their generous support during the study.

Received: October 16, 2009

[1] R. K. Merton, Am. Sociol. Rev. 1957, 22, 635.

[2] C. G. Jennings, 'Quality and value: the true purpose of peer review. What you can't measure, you can't manage: the need for quantitative indicators in peer review', retrieved July 6, 2006, from http://www.nature.com/nature/peerreview/ debate/nature05032.html, 2006

[3] O. F. Azar, Int. J. Soc. Econ. 2004, 31, 259.

[4] I. Hames, 'Peer review and manuscript management of scientific journals: guidelines for good practice', Blackwell, Oxford, UK, 2007.

[5] Publishing Research Consortium, 'Peer review in scholarly journals: perspective of the scholarly community - an international study', Publishing Research Consortium, Bristol, UK, 2008.

[6] O. Mryglod, Y. Holovatch, 'Towards journalometrical analysis of a scientific periodical: a case study', retrieved May 5, from http://arxiv.org/ abs/0707.3696, 2008

[7] P. Gupta, G. Kaur, B. Sharma, D. Shah, P. Choudhury, Indian Pediatrics 2006, 43, 479.

[8] T. Stamm, U. Meyer, H.-P. Wiesmann, J. Kleinheinz, M. Cehreli, C. C. Zafer, Head Face Med. 2007, 3, 27.

[9] S. M. Green, M. L. Callaham, Ann. Emerg. Med 2006, $48,304$.

[10] J. Ely, M. Woolley, F. Lynch, J. McDonald, L. Findlay, Y. Choi, K. Woolley, in 5th International Congress on Peer Review and Biomedical Publication, Eds. D. Rennie, F. Godlee, A. Flanagin, J. Smith, Chicago, IL, USA, 2005.

[11] L. Bornmann, H.-D. Daniel, J. Am. Soc. Inf. Sci. Tec. 2008, 59, 1841.

[12] L. Bornmann, H.-D. Daniel, Angew. Chem. Int Ed. 2008, 47, 7173 .

[13] L. Bornmann, H.-D. Daniel, Learned Publishing 2009, 22, 117

[14] L. Bornmann, C. Weymuth, H.-D. Daniel, Scientometrics, doi:10.1007/s11192-009-00114.

[15] G. Yu, Y. J. Li, D. R. Yu, J. Inf. Sci. 2009, 35, 414

[16] Association of Learned and Professional Society Publishers, 'Current practice in peer review. Results of a survey conducted during Oct/Nov 2000', Association of Learned and Professional Society Publishers, Worthing, UK, 2000.

[17] L. Bornmann, H.-D. Daniel, Libr. Inf. Sci. Res. doi:10.1016/j.lisr.2009.07.010.

[18] H.-D. Daniel, 'Guardians of science. Fairness and reliability of peer review', Wiley-VCH, Weinheim, Germany, 1993.

[19] P. Gölitz, Angew. Chem. Int. Ed. 2005, 44, 5538.

[20] R. M. Conroy, Stata J. 2002, 2, 290.

[21] R. B. Kline, 'Beyond significance testing: reforming data analysis methods in behavioral research', American Psychological Association, Washington, DC, USA, 2004.

[22] J. Cohen, 'Statistical power analysis for the behavioral sciences', 2nd ed., Lawrence Erlbaum Associates, Publishers, Hillsdale, NJ, USA, 1988.

[23] D. R. de Vries, E. A. Marschall, R. A. Stein, Fisheries 2009, 34, 270.

[24] P. Gölitz, Angew. Chem. Int. Ed. 2006, 45, 5030.

[25] Journal of the American Chemical Society, 'Guidelines for Authors', retrieved July 10, 2008 , from http://pubs.acs.org/paragonplus/submission/jacsat/jacsat_authguide.pdf, 2008.

[26] C. Neuhaus, W. Marx, H.-D. Daniel, J. Am. Soc. Inf. Sci. Technol. 2009, 60, 176.

[27] P. Gölitz, Angew. Chem. Int. Ed. 2008, 47, 7144. 